PREPARED FOR THE U.S. DEPARTMENT OF ENERGY, UNDER CONTRACT DE-AC02-76CH03073

PPPL-3853

PPPL-3853

UC-70

Measurements of Plasma Expansion due to Background Gas in the Electron Diffusion Gauge Experiment

by

Kyle A. Morrison, Stephen F. Paul, and Ronald C. Davidson

August 2003

$N_{\substack{\text { PRInCETOn PLASMA } \\ \text { PHYSIES LABORATORY }}}^{D}$

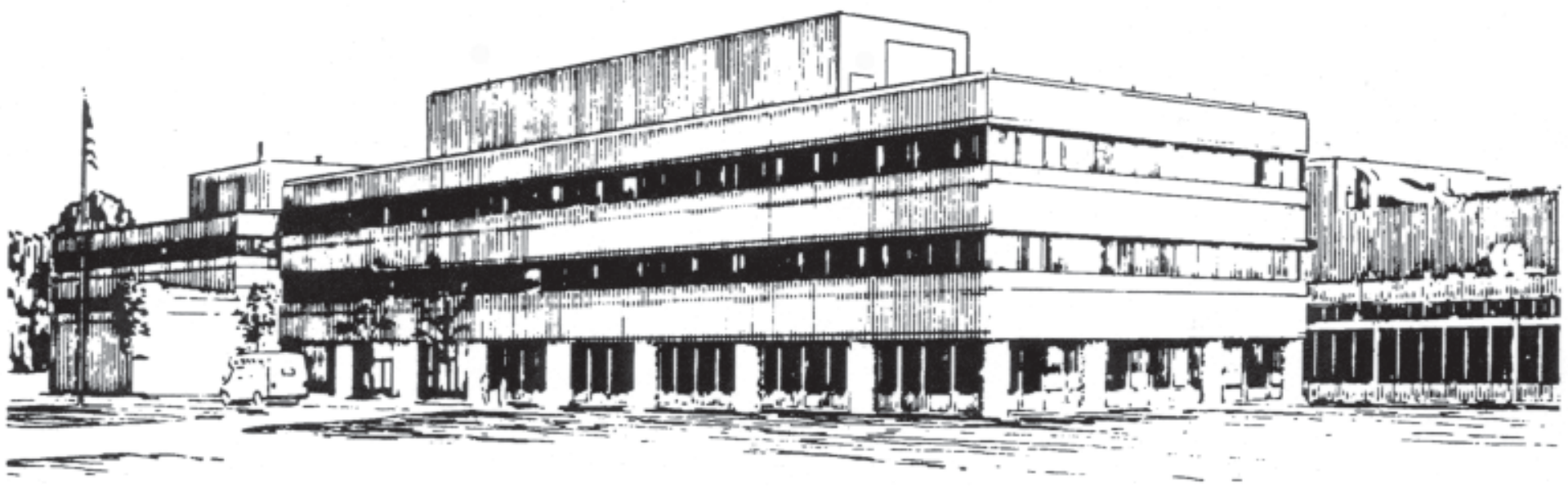

PRINCETON PLASMA PHYSICS LABORATORY PRINCETON UNIVERSITY, PRINCETON, NEW JERSEY 


\section{PPPL Reports Disclaimer}

This report was prepared as an account of work sponsored by an agency of the United States Government. Neither the United States Government nor any agency thereof, nor any of their employees, makes any warranty, express or implied, or assumes any legal liability or responsibility for the accuracy, completeness, or usefulness of any information, apparatus, product, or process disclosed, or represents that its use would not infringe privately owned rights. Reference herein to any specific commercial product, process, or service by trade name, trademark, manufacturer, or otherwise, does not necessarily constitute or imply its endorsement, recommendation, or favoring by the United States Government or any agency thereof. The views and opinions of authors expressed herein do not necessarily state or reflect those of the United States Government or any agency thereof.

\section{Availability}

This report is posted on the U.S. Department of Energy's Princeton Plasma Physics Laboratory Publications and Reports web site in Fiscal Year 2003. The home page for PPPL Reports and Publications is: http://www.pppl.gov/pub_report/

DOE and DOE Contractors can obtain copies of this report from:

U.S. Department of Energy

Office of Scientific and Technical Information

DOE Technical Information Services (DTIS)

P.O. Box 62

Oak Ridge, TN 37831

Telephone: (865) 576-8401

Fax: (865) 576-5728

Email: reports@adonis.osti.gov

This report is available to the general public from:

National Technical Information Service

U.S. Department of Commerce

5285 Port Royal Road

Springfield, VA 22161

Telephone: $1-800-553-6847$ or

(703) $605-6000$

Fax: (703) 321-8547

Internet: http://www.ntis.gov/ordering.htm 


\title{
Measurements of Plasma Expansion due to Background Gas in the Electron Diffusion Gauge Experiment
}

\author{
Kyle A. Morrison, Stephen F. Paul, and Ronald C. Davidson \\ Plasma Physics Laboratory, Princeton University, Princeton, NJ 08543
}

\begin{abstract}
The expansion of pure electron plasmas due to collisions with background neutral gas atoms in the Electron Diffusion Gauge experiment device is observed. Measurements of plasma expansion with the new, phosphor-screen density diagnostic suggest that the expansion rates measured previously were observed during the plasma's relaxation to thermal quasi-equilibrium, making it even more remarkable that they scale classically with pressure. Measurements of the on-axis, parallel plasma temperature evolution support the conclusion.
\end{abstract}

\section{INTRODUCTION}

Pure electron plasmas are trapped in the Electron Diffusion Gauge (EDG) experiment device [1-4], a cylindrically symmetric, Malmberg-Penning trap [5-12] with inside diameter I.D. $=2 \cdot \mathrm{R}_{\mathrm{w}}=5.08 \mathrm{~cm}$. Malmberg-Penning traps have a uniform magnetic field parallel to the common axis of several cylindrical electrodes, and particles with the same sign of charge can be confined by charging two nonadjacent electrodes to a sufficiently large voltage. Previously reported experimental results [2] from the EDG experiment indicate that the plasma expansion rates measured in the high-vacuum regime (where asymmetry-induced expansion is negligible) are in good agreement with with the predicted expansion rates [13] derived using a warm fluid treatment of the plasma. The evolution of the inferred perpendicular temperature during this expansion, however, did not account for the clear decrease in electrostatic potential energy, prompting improvements to the EDG diagnostic systems.

Previously, axially-integrated density profiles obtained from the EDG experiment were accumulated from a series of plasmas by measuring the number of electrons passing through a small hole in a radially-movable collimating plate. The particles moving along magnetic field lines aligned with the small hole in the plate would pass through to a Faraday cup, giving a radial profile as the collimating plate was scanned. By forming several (well-reproduced) plasmas in succession, a series of line-integrated, radial density profiles could be obtained and used to follow the expansion of the plasma. To determine the plasma behavior at different gas pressures, helium gas was fed into the chamber at different, controlled rates. 


\section{ELECTRON DENSITY AND TEMPERATURE DIAGNOSTICS}

The Faraday cup density diagnostic has been replaced with a CCD camera focused on a biased, phosphor-coated glass screen, a setup based on the diagnostics developed by other groups $[14,15]$. The phosphor is coated with aluminum both to reflect excess light from the plasma source (a $1.27 \mathrm{~cm}$-diameter spiral filament) and act as an additional electrode. The aluminum coating is biased to a few kilovolts to accelerate the plasma electrons to the point that they can pass through it and excite the phosphor molecules. The light emitted by the phosphor passes through the glass screen, a glass vacuum window, a notch filter tuned to the peak emission wavelength of the P-43 phosphor, a camera lens, and a separate image intensifier on its way to the CCD camera. A grounded (10 wires/inch) copper grid is attached to the end of the trap, about 1 inch away from the biased screen, to make the accelerating electric field more uniform. Figure 1 shows the improved resolution of the phosphor-screen diagnostic.
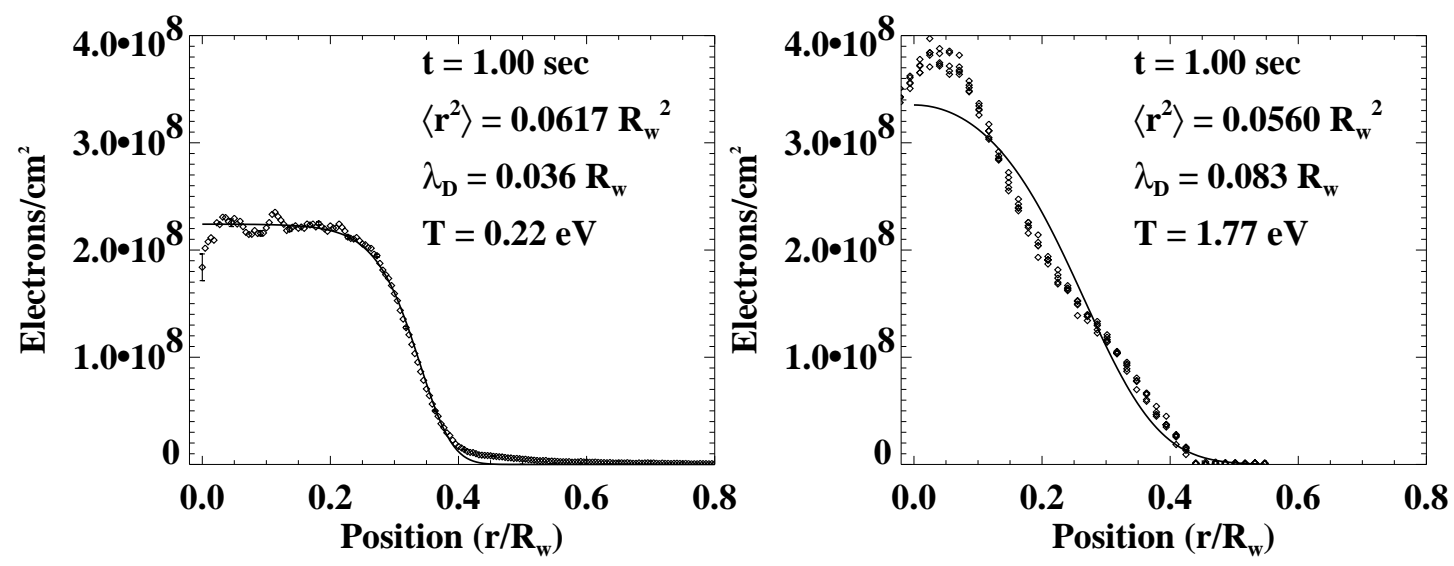

FIGURE 1. The figure on the left shows an example of the CCD-image-derived profiles, overlaid with a thermal quasi-equilibrium profile. The figure on the right shows an example of data obtained with the Faraday cup diagnostic, where each data point is from a different plasma.

The perpendicular electron temperatures displayed in Fig. 1 are estimated by fitting an ideal, thermal quasi-equilibrium density profile [13] to the measured, axially-integrated profile. The thermal quasi-equilibrium profile is

$$
n(r, t)=\hat{n}(t) \exp \left\{\frac{e \phi(r, t)-e \hat{\phi}(t)}{T}-\frac{r^{2}}{\left\langle r^{2}\right\rangle(t)}\left(1+\frac{N_{L} e^{2}}{2 T}\right)\right\}
$$

Here, $\hat{n}(t)$ is the central density as a function of time, $\phi(r, t)$ is the electrostatic potential, and $\hat{\phi}(t)$ is the electrostatic potential on axis $(r=0)$. This thermal quasiequilibrium profile describes expanding, infinite-length, azimuthally symmetric plasmas that enjoy global energy conservation and elastic electron-neutral collisions, and have a spatially uniform temperature. Poisson's equation can be recast in a form that shows the underlying profile shape is dependent on only one parameter, $\gamma$, defined by $\gamma \equiv\left(\omega_{r} \omega_{c e}-\omega_{r}^{2}\right) /\left(\hat{\omega}_{p}^{2} / 2\right)-1$, where $\omega_{c e}=e B / m_{e} c$ is the electron cyclotron frequency, $\omega_{r}$ is the plasma rotation frequency, and $\hat{\omega}_{p}$ is the plasma frequency at $r=0 . \gamma$ is the 
only parameter necessary to describe the ideal density profiles. We also allow $\hat{n}(t)$ to vary in the fit for simplicity, though in principle it should be identifiable from the data.

On-axis parallel temperature measurements are performed as described by Eggleston [16]: the charge on one of the confining electrodes is slowly decreased, and the number of electrons escaping the trap as a function of time is recorded. The results are fit using the approximate relationship

$$
\frac{\mathrm{d} \ln \left(Q_{\mathrm{esc}}\right)}{\mathrm{d}\left(\mathrm{e} \phi_{\mathrm{c}}\right)}=\frac{-1.05}{T_{\|}},
$$

where $Q_{\text {esc }}$ is the total amount of charge that has escaped, -e is the charge of an electron, $\phi_{c}$ is the confining voltage on axis, and $T_{\|}$is the parallel temperature in eV. In EDG, a charge-sensitive amplifier is capacitively coupled to the biased phosphor screen to measure the total charge that has escaped as a function of time. Typical plots of both $\ln \left(Q_{\text {esc }}\right)$ versus $\phi_{c}$ and $Q_{\text {esc }}$ versus $\phi_{c}$ are displayed in Fig. 2.

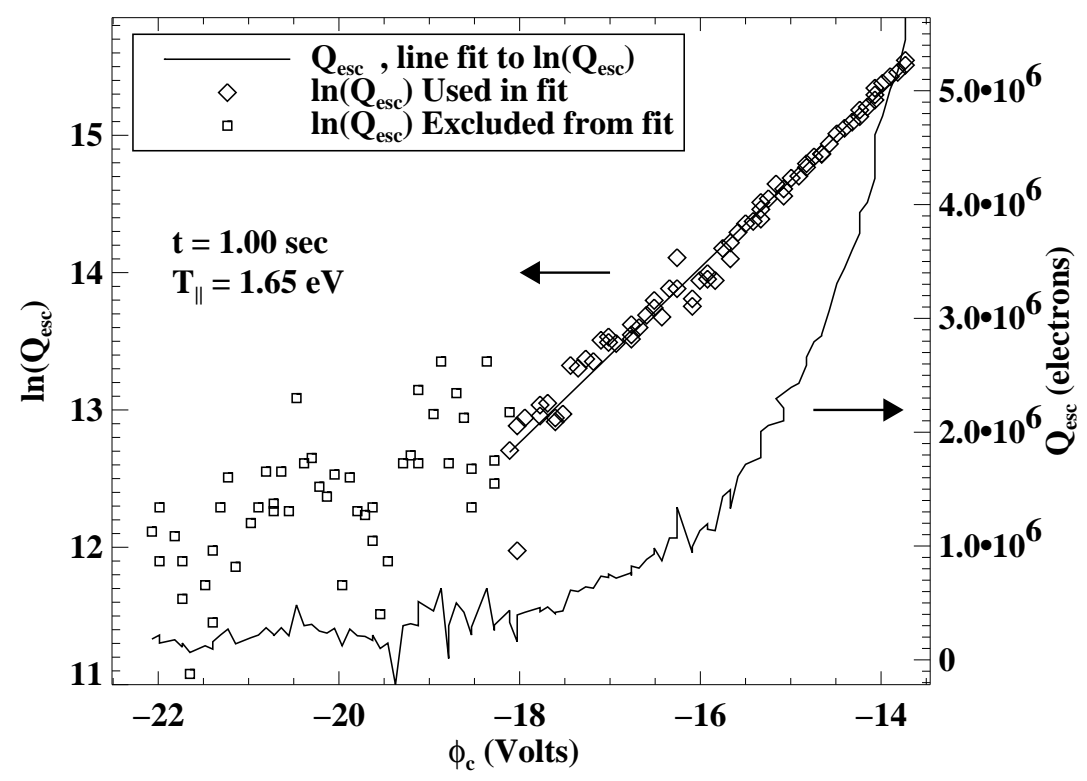

FIGURE 2. Total charge escaped versus confining voltage as a plasma is released from the trap. The diamonds denote the data used in the fit. This data was taken at magnetic field $B=600 G$, background gas pressure $\mathrm{P} \sim 5 \times 10^{-9}$ Torr, filament heating voltage $\mathrm{V}_{\mathrm{h}}=4.8 \mathrm{~V}$, and filament bias voltage (the voltage at the center of the spiral filament) $\mathrm{V}_{\mathrm{b}}=-16.6 \mathrm{~V}$. This plasma comprised $N \sim 5 \times 10^{8}$ electrons.

\section{MEASUREMENT OF PLASMA EXPANSION}

The plasma's expansion rate is computed as the rate of change of its mean-square radius. The mean-square radius is approximated by

$$
\left\langle r^{2}\right\rangle=\frac{\int_{0}^{R_{w}} d r 2 \pi r r^{2} Q(r)}{\int_{0}^{R_{w}} d r 2 \pi r Q(r)},
$$


where $Q(r)$ is the axially-integrated density profile determined from one of the density diagnostics. For the Faraday cup diagnostic, $Q(r)$ corresponds to the axially-integrated density averaged over the collimating hole area (radius $=0.159 \mathrm{~cm}$ ) at location $r$. For the phosphor-screen diagnostic, it corresponds to the axially integrated density averaged azimuthally between $r$ and $r+d r(d r \sim .012 \mathrm{~cm}$, the width on the screen of one camera pixel's view).

Because many plasmas were needed to construct one measured density profile using the Faraday cup diagnostic and the trap conditions tend to drift with time, it was impossible to make profile measurements for plasmas held in the trap much longer than a second. The new, phosphor-screen density diagnostic measures the entire, axiallyintegrated density profile of a single plasma, allowing us to measure the evolution well past 1 second. The data in Fig. 3 show that the plasma behaves differently after it has been confined for about 3 seconds than it does initially.

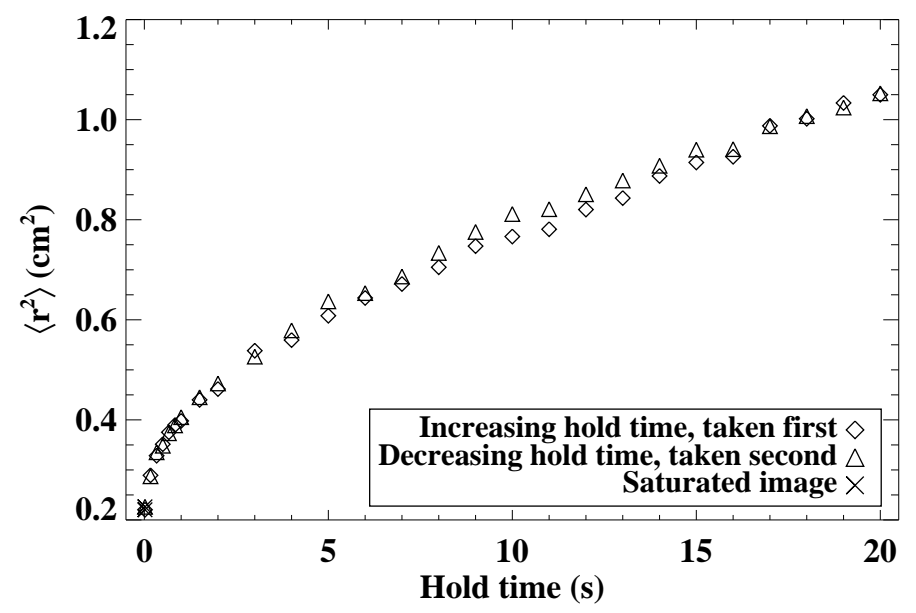

FIGURE 3. Plasma mean square radius as a function of time for the same experimental parameters as the data in Fig. 2. The agreement between the increasing hold time and decreasing hold time data indicate the plasma's reproducibility.

The density profiles for plasmas trapped longer than 3 seconds are fit somewhat better by the thermal quasi-equilibrium profiles than those for plasmas trapped for less time, but the inferred temperatures from the profile fits, shown in Fig. 4, hardly vary throughout the evolution. The parallel temperatures also shown in Fig. 4, however, rise dramatically at the beginning of the evolution. In addition, the initial evolutions of the plasma mean square radius and the parallel temperature appear to take the same amounts of time at several different filament conditions and background gas pressures below $\mathrm{P}$ $\sim 2 \times 10^{-7}$ Torr. The initial evolution of the plasmas in Fig. 3 may be due primarily to a transition to thermal quasi-equilibrium from an initially non-equilibrium state, rather than expansion due to background gas or trap asymmetries. The disagreement between the two temperature diagnostics is not presently understood.

The expansion rates measured previously on EDG were determined from plasmas trapped less than 1 second, meaning that they were computed from plasmas experiencing this apparent relaxation to thermal quasi-equilibrium. Figure 5 shows a comparison of 

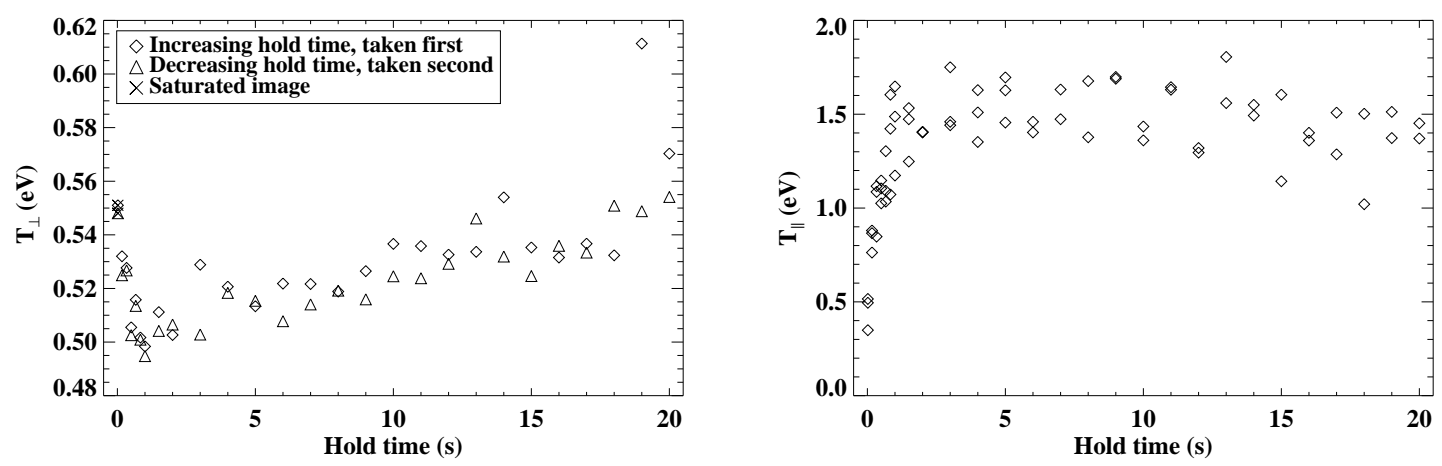

FIGURE 4. The inferred perpendicular temperature (left) and measured, on-axis parallel temperature evolution (right) for the same experimental parameters as the data in Fig. 2.

'late-time' expansion rates determined from the new profile data (excluding the initial relaxation, where possible) to the expansion rates measured previously. Note that while the older expansion rates start to level off to a value of about $0.1 \mathrm{~cm}^{2} / \mathrm{s}$ as the background gas pressure decreases, the late-time expansion rates are clearly smaller. Estimating expansion rates from the first 1 second of phosphor-screen profile data gives values that agree with the $0.1 \mathrm{~cm}^{2} / \mathrm{s}$ value measured previously at low pressures. The late-time expansion rates still level off at the lowest pressures, indicating that asymmetry-induced expansion is indeed affecting the measurements.

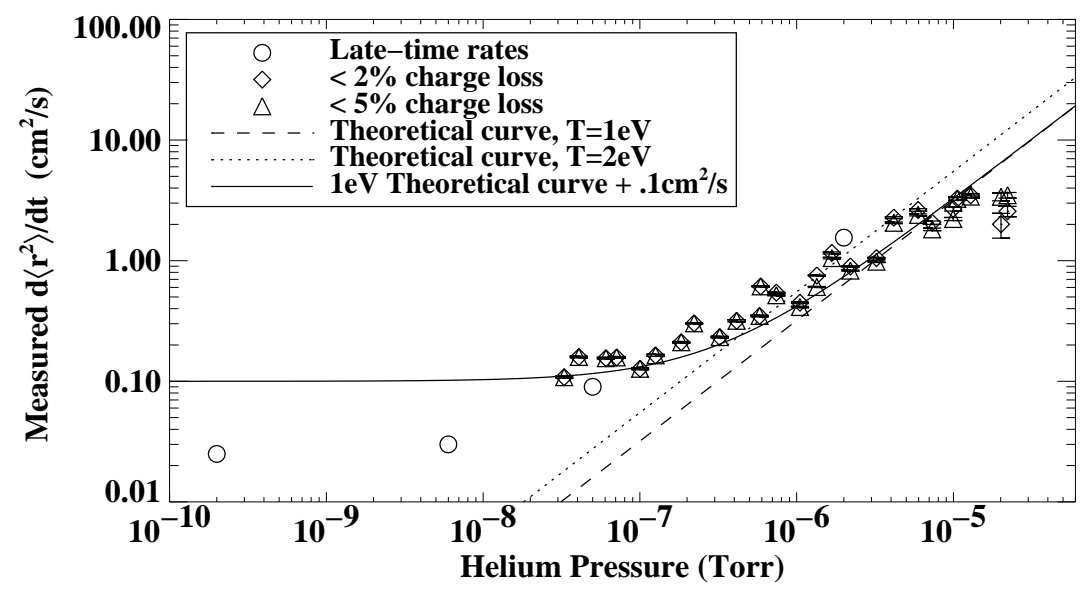

FIGURE 5. Comparison of expansion rates determined from the previous and present density diagnostics. The circles denote the new expansion rates computed by excluding the initial plasma relaxation at lower pressures.

The plasma expansion rate calculated [13] for thermal quasi-equilibrium profiles affected by background neutral gas is

$$
\frac{d}{d t}\left\langle r^{2}\right\rangle=\frac{2 N_{L} e^{2} v_{e n}(T)}{m_{e} \omega_{c e}^{2}}\left(1+\frac{2 T}{N_{L} e^{2}}\right),
$$


where $v_{e n}(T)=n_{n} \sigma_{e n} v_{T h}$ is the electron-neutral collision frequency, $T$ is the plasma temperature (in ergs), and $N_{L}$ is the line density of the plasma column. The theoretical curves in Fig. 5 agree with the data at higher pressures fairly well, despite the fact that the collisionally-induced expansion is superimposed upon the initial relaxation measured at lower pressures. Accordingly, we may infer that the fact that the plasma is not fully in thermal quasi-equilibrium does not prevent it from expanding at the same rate that a plasma in thermal quasi-equilibrium would. At high-vacuum pressures (above $\mathrm{P} \sim 2 \times 10^{-7}$ Torr), the electron-neutral collision frequency is higher than the electronelectron collision frequency, so the temperature gradients that could exist in the plasma are also having a minimal effect on the classical expansion rate of the electron plasmas in EDG.

\section{ACKNOWLEDGMENTS}

This research was supported by the Office of Naval Research, and in part supported by the U.S. Department of Energy.

\section{REFERENCES}

1. Chao, E. H., Davidson, R. C., Paul, S. F., and Morrison, K. A., Phys. Plasmas, 7, 831-838 (2000).

2. Morrison, K. A., Davidson, R. C., Paul, S. F., Belli, E. A., and Chao, E. H., Phys. Plasmas, 8, 3506-3509 (2001).

3. Chao, E. H., Davidson, R. C., Paul, S. F., and Morrison, K. A., "Effects of Background Gas Pressure on Pure Electron Plasma Dynamics in the Electron Diffusion Gauge Experiment," in Proceedings of the 1999 Workshop on Nonneutral Plasmas: AIP Conference Proceedings 498, edited by J. Bollinger, R. C. Davidson, and R. Spencer, American Institute of Physics, Melville, NY, 1999, pp. 278-289.

4. Morrison, K. A., Davidson, R. C., Paul, S. F., and Jenkins, T. G., "Investigation of the Expansion Rate Scaling of Plasmas in the Electron Diffusion Gauge Experiment., in Non-Neutral Plasma Physics IV: Workshop on Non-Neutral Plasmas: AIP Conference Proceedings, Volume 606, edited by F. Anderegg, L. Schweikhard, and C. F. Driscoll, American Institute of Physics, Melville, NY, 2002, pp. 416-421.

5. deGrassie, J. S., and Malmberg, J. H., Phys. Rev. Lett., 39, 1077-1080 (1977).

6. O'Neil, T. M., Phys. Scripta, 59, 341-351 (1995).

7. Gould, R. W., Phys. Plasmas, 2, 2151-2163 (1995).

8. Driscoll, C. F., Anderegg, F., Dubin, D. H. E., Jin, D. Z., Kriesel, J. M., Hollmann, E. M., and O’Neil, T. M., Phys. Plasmas, 9, 1905-1914 (2002).

9. Anderegg, F., Shiga, N., Dubin, D. H. E., Driscoll, C. F., and Gould, R. W., Phys. Plasmas, 10, 1556-1562 (2003).

10. Bollinger, J. J., Kriesel, J. M., Mitchell, T. B., King, L. B., Jensen, M. J., Itano, W. M., and Dubin, D. H. E., J. Phys. B, 36, 499-510 (2003).

11. Greaves, R. G., and Surko, C. M., Nucl. Instrum. Meth. B, 192, 90-96 (2002).

12. Fajans, J., Gilson, E., and Backhaus, E. Y., Phys. Plasmas, 7, 3929-3933 (2000).

13. Davidson, R. C., and Moore, D. A., Phys. Plasmas, 3, 218-225 (1996).

14. Peurrung, A. J., and Fajans, J., Rev. Sci. Instrum., 64, 52-55 (1993).

15. Huang, X.-P., Fine, K. S., and Driscoll, C. F., Phys. Rev. Lett., 74, 4424-4427 (1995).

16. Eggleston, D. L., Driscoll, C. F., Beck, B. R., Hyatt, A. W., and Malmberg, J. H., Phys. Fluids B, 4, 3432-3439 (1992). 


\section{External Distribution}

Plasma Research Laboratory, Australian National University, Australia

Professor I.R. Jones, Flinders University, Australia

Professor João Canalle, Instituto de Fisica DEQ/IF - UERJ, Brazil

Mr. Gerson O. Ludwig, Instituto Nacional de Pesquisas, Brazil

Dr. P.H. Sakanaka, Instituto Fisica, Brazil

The Librarian, Culham Laboratory, England

Mrs. S.A. Hutchinson, JET Library, England

Professor M.N. Bussac, Ecole Polytechnique, France

Librarian, Max-Planck-Institut für Plasmaphysik, Germany

Jolan Moldvai, Reports Library, Hungarian Academy of Sciences, Central Research Institute for Physics, Hungary

Dr. P. Kaw, Institute for Plasma Research, India

Ms. P.J. Pathak, Librarian, Institute for Plasma Research, India

Ms. Clelia De Palo, Associazione EURATOM-ENEA, Italy

Dr. G. Grosso, Instituto di Fisica del Plasma, Italy

Librarian, Naka Fusion Research Establishment, JAERI, Japan

Library, Laboratory for Complex Energy Processes, Institute for Advanced Study, Kyoto University, Japan

Research Information Center, National Institute for Fusion Science, Japan

Dr. O. Mitarai, Kyushu Tokai University, Japan

Dr. Jiangang Li, Institute of Plasma Physics, Chinese Academy of Sciences, People's Republic of China

Professor Yuping Huo, School of Physical Science and Technology, People's Republic of China

Library, Academia Sinica, Institute of Plasma Physics, People's Republic of China

Librarian, Institute of Physics, Chinese Academy of Sciences, People's Republic of China

Dr. S. Mirnov, TRINITI, Troitsk, Russian Federation, Russia

Dr. V.S. Strelkov, Kurchatov Institute, Russian Federation, Russia

Professor Peter Lukac, Katedra Fyziky Plazmy MFF UK, Mlynska dolina F-2, Komenskeho Univerzita, SK-842 15 Bratislava, Slovakia

Dr. G.S. Lee, Korea Basic Science Institute, South Korea

Institute for Plasma Research, University of Maryland, USA

Librarian, Fusion Energy Division, Oak Ridge National Laboratory, USA

Librarian, Institute of Fusion Studies, University of Texas, USA

Librarian, Magnetic Fusion Program, Lawrence Livermore National Laboratory, USA

Library, General Atomics, USA

Plasma Physics Group, Fusion Energy Research Program, University of California at San Diego, USA

Plasma Physics Library, Columbia University, USA

Alkesh Punjabi, Center for Fusion Research and Training, Hampton University, USA

Dr. W.M. Stacey, Fusion Research Center, Georgia Institute of Technology, USA

Dr. John Willis, U.S. Department of Energy, Office of Fusion Energy Sciences, USA

Mr. Paul H. Wright, Indianapolis, Indiana, USA 
The Princeton Plasma Physics Laboratory is operated by Princeton University under contract with the U.S. Department of Energy.

\author{
Information Services \\ Princeton Plasma Physics Laboratory \\ P.O. Box 451 \\ Princeton, NJ 08543
}

Phone: 609-243-2750

Fax: 609-243-2751

e-mail: pppl_info@pppl.gov

Internet Address: http://www.pppl.gov 